\title{
Prognostic Significance of Pre-surgical Combined Platelet Count and Neutrophil-Lymphocyte Ratio for Patients With Hepatocellular Carcinoma
}

\author{
EI UCHINAKA, MASATAKA AMISAKI, TAKUKI YAGYU, MASAKI MORIMOTO, \\ JOJI WATANABE, NARUO TOKUYASU, TERUHISA SAKAMOTO, \\ SOICHIRO HONJO, HIROAKI SAITO and YOSHIYUKI FUJIWARA \\ Division of Surgical Oncology, Department of Surgery, School of Medicine, \\ Tottori University Faculty of Medicine, Yonago, Japan
}

\begin{abstract}
Background/Aim: Recent studies have investigated a novel inflammation-based prognostic system using the combination of platelet count and neutrophil-lymphocyte ratio (COP-NLR). As platelet count decreases with liver damage, we hypothesized that COP-NLR could indicate both inflammation and hepatic reserve in patients with hepatocellular carcinoma (HCC). This study was conducted to clarify the prognostic significance of preoperative COP-NLR in patients with HCC. Patients and Methods: We enrolled 176 patients with histologically-proven HCC who underwent initial curative hepatectomy. Patients were assigned one point each for low platelet count $\left(<15 \times 10^{4} / \mu l\right)$ or for high NLR $(\geq 2.0)$, for hepatic-COP-NLR scores (h-COP-NLR) of 0, 1 or 2. Results: Five-year overall survival $(O S)$ and recurrence-free survival (RFS) rates were $74.5 \pm 9 \%$, and $62.2 \% \pm 9.3 \%$ for score 0 , $63.6 \pm 5.4 \%$ and $50.3 \% \pm 5.6 \%$ for score 1 , and $45.2 \pm 8.8 \%$ and $40.6 \pm 8.7 \%$ for score 2 , respectively, and significantly differed (OS: $p=0.01 ; R F S: p=0.03)$. In multivariate analysis, $h$-COP$N L R$ was an independent risk factor for tumor recurrence $(H R=1.39, p=0.03)$ and death (HR=1.71, $p=0.02)$. Conclusion: h-COP-NLR was an independent predictor for prognosis of HCC patients after hepatic resection.
\end{abstract}

Worldwide, hepatocellular carcinoma (HCC) is the fifth most common cancer diagnosis and the third leading cause of cancer

This article is freely accessible online.

Correspondence to: Masataka Amisaki, MD, Division of Surgical Oncology, Department of Surgery, School of Medicine, Tottori University Faculty of Medicine, 36-1 Nishi-cho, Yonago 683-8504, Japan. Tel: +81 859386567, Fax: +81 859386569, e-mail: amisakim@med.tottori-u.ac.jp

Key Words: Liver resection, prognosis, predictive factor. mortality (1). Patients' mean age at HCC diagnosis is 65.7 years (2). Although diagnosis and treatment are progressing, the overall prognosis of HCC remains poor, with an estimated 5 -year survival rate of only $12 \%$ (3). Accurate risk stratification is essential to optimize treatment for patients with HCC.

Systemic inflammation and immunological status in cancer patients are closely related to cancer progression $(4,5)$. As inflammation and immunological status can be assessed with serological analyses, several prognostic indices based on markers of inflammation have been proposed, including the neutrophil-to-lymphocyte ratio (NLR), the Glasgow Prognostic Score, and the platelet to lymphocyte ratio for patients with malignancies, including HCC (6-9). A novel inflammation-based prognostic system that uses the combination of platelet count and NLR (COP-NLR) has been recently proposed (10-14). Supporting studies have shown COP-NLR to be a useful predictor of postoperative survival in patients with renal cell carcinoma, esophageal squamous cell carcinoma, head and neck cancer, non-small cell lung cancer and colorectal cancer (10-14). However, its prognostic reliability has not been assessed for $\mathrm{HCC}$ patients who undergo curative surgery. One reason for this is, whereas inflammation from most malignancies leads to higher platelet counts $(15,16)$, in patients with HCC arising from liver disease, low liver function leads to lower platelet counts (17).

Therefore, the predictive significance of both platelet count alone and COP-NLR should be evaluated for patients with HCC. We hypothesized that COP-NLR indicates both inflammation and hepatic reserve among patients with HCC. This study analyzed the prognostic significance of preoperative COP-NLR in patients with HCC.

\section{Patients and Methods}

Patients. This study enrolled 176 patients with histologically-proven HCC who underwent initial and curative hepatectomies at Tottori 


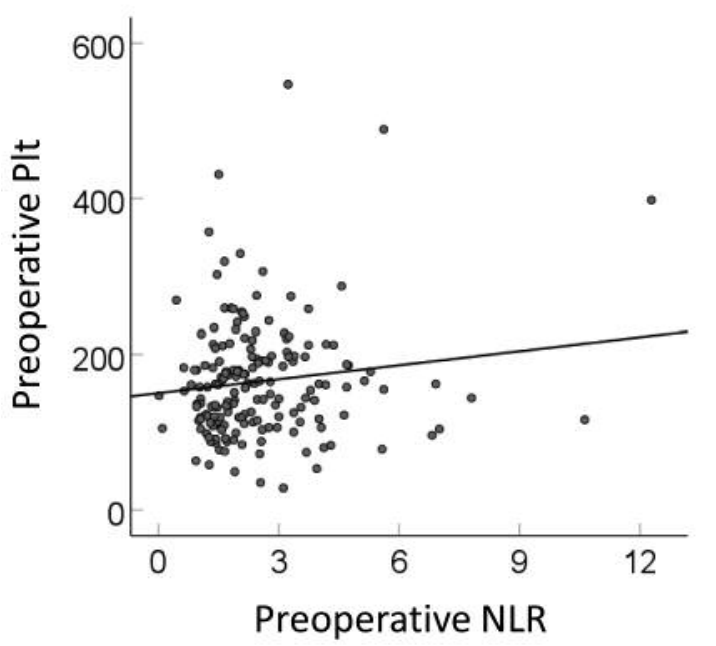

Figure 1. Preoperative NLR and preoperative Plt in patients with HCC showed no statistically significant correlation $(r=0.106 ; p=0.160)$.

University Hospital between 2004 and 2013. As this was a retrospective study, all clinicopathological data were collected from medical records. Pathological findings were classified according to the 5th edition of The General Rules for the Clinical and Pathological Study of Primary Liver Cancer (18). After surgery, patients were routinely followed up for disease recurrence with measurements of serum tumor markers and imaging modalities such as ultrasonography, computed tomography, or magnetic resonance imaging were used every six months to detect disease recurrence. Follow-up was calculated from the day of surgery to the day of death or the last visit. Information on the cause of death and type of recurrence were obtained from medical records.

Pre-operative NLR was defined as the absolute neutrophil count divided by the absolute lymphocyte count obtained from blood tests (19) within a week before surgery. Cut-off values of pre-operative NLR and platelet counts were derived from receiver operating characteristic (ROC) analyses. Based on these cutoff values, enrolled patients were divided into the following three groups; those in whom both values were normal (scored as 0 ), in whom one value was unfavorable (scored as 1), and in whom both values were unfavorable (scored as 2).

Statistical analysis. All statistical analyses were carried out with SPSS version 25 (IBM, NY, USA). Overall survival (OS) and recurrencefree survival (RFS) rates were calculated according to the KaplanMeier method and compared using the log-rank test. OS was calculated from the date of surgery to the date of death or last visit. RFS was calculated from the date of surgery to the date of disease recurrence or last visit. Seventeen clinicopathological factors, including age, sex, hepatitis B surface antigen (HBsAg), hepatitis C virus (HCV), diabetes mellitus, NLR, platelet count, alpha-fetoprotein (AFP), surgical duration, extent of resection, number of tumors, tumor size, histological subtype, microscopic portal vein invasion (vp), TNM stage, liver cirrhosis, and COP-NLR were entered in the univariate analysis. Clinicopathological factors for which $p<0.05$ were further analyzed in multivariate analyses to determine the independent predictors for OS. Hazard ratios (HR) and 95\% confidence intervals (CI) were calculated for all estimates. $p<0.05$ was considered significant. All continuous values are presented as mean \pm standard deviation.

\section{Results}

Among the 176 patients with HCC, 147 (83.5\%) were men and $29(16.5 \%)$ were women. Their mean age was $68.1 \pm 9.6$ years. The mean follow-up period was $46.6 \pm 33.1$ months. Mean platelet count and NLR were $16.6 \pm 7.53 \times 10^{4} / \mu \mathrm{l}$ and $2.51 \pm 1.64$, respectively. As platelet count and NLR showed no statistically significant correlation ( $\mathrm{r}=0.106, p=0.160$; Figure $1)$, the combination of these two values might be reasonably expected to more accurately predict patients' prognosis. ROC analysis showed the optimal pre-operative cutoff values to be NLR: 2.0 (area under the curve [AUC]: $0.585, p=0.054$ ), and platelet count: $15 \times 10^{4} / \mu \mathrm{l}$ (AUC: $0.600, p=0.023$; Figure 2). Kaplan-Meier analysis according to NLR or platelet counts showed that patients with high NLR or low platelet count tended to have lower 5-year OS rates (Figure 3).

According to these results, hepatic-COP-NLR (h-COPNLR) 2 was defined as both high NLR $(\geq 2.0)$ and decreased platelet count $\left(<15 \times 10^{4} / \mu 1\right)$. The one that allowed only one was defined as h-COP-NLR 1 . The thing which neither admits was defined as h-COP-NLR 0 . Of the 176 patients, 38 had hCOP-NLR 0, 98 had h-COP-NLR 1, and 40 had h-COP-NLR 2. In ROC analysis, AUC of the combination of platelet count and NLR for OS was 0.620, which was higher than those of either platelet count or NLR considered separately (Figure 4).

Table I shows the correlation of clinicopathological factors between the h-COP-NLR $=0,1$, and 2 groups. These three groups did not significantly differ in clinical features (Table I). Kaplan-Meier curves and log rank tests showed that 5-year OS rates were $74.5 \pm 9 \%$ in h-COP-NLR $0,63.6 \pm 5.4 \%$ in h-COPNLR 1, and $45.2 \pm 8.8 \%$ in h-COP-NLR 2, with significant differences ( $p=0.005$; Figure 5a;). Five-year recurrence-free survival rates were $62.2 \% \pm 9.3 \%$ in h-COP-NLR 0 , $50.3 \% \pm 5.6 \%$ in h-COP-NLR 1 , and $40.6 \pm 8.7 \%$ in h-COP-NLR $2(p=0.033$; Figure $5 \mathrm{~b})$. Thus, pre-operative h-COP-NLR successfully stratified patients by prognosis. In the univariate analyses for predictors of death from all causes, h-COP-NLR was significantly predictive $(\mathrm{HR}=1.768,95 \% \mathrm{CI}=1.238-2.525$, $p=0.002)$. Other identified prognostic factors were NLR ( $\mathrm{HR}=1.810,95 \% \mathrm{CI}=1.128-2.903, p=0.014)$, and TNM stage $(\mathrm{HR}=2.319,95 \% \mathrm{CI}=1.204-4.464, p=0.012)$. However, low platelet counts alone had no prognostic significance $(\mathrm{HR}=1.463$, $95 \% \mathrm{CI}=0.923-2.318, p=0.106)$. Multivariate analysis confirmed that h-COP-NLR $(\mathrm{HR}=1.714,95 \% \mathrm{CI}=1.073-2.739, p=0.024)$, and TNM stage $(\mathrm{HR}=2.450,95 \% \mathrm{CI}=1.261-4.759, p=0.008)$ were independent prognostic factors (Table II). In univariate analysis for disease recurrence, h- COP-NLR (HR=1.452, 95\% CI $=1.081-1.948, p=0.013)$, $\operatorname{sex}(\mathrm{HR}=1.638,95 \% \mathrm{CI}=1.003-$ 2.677, $p=0.049)$, AFP $(\mathrm{HR}=1.531,95 \% \mathrm{CI}=1.041-2.251$, 
a

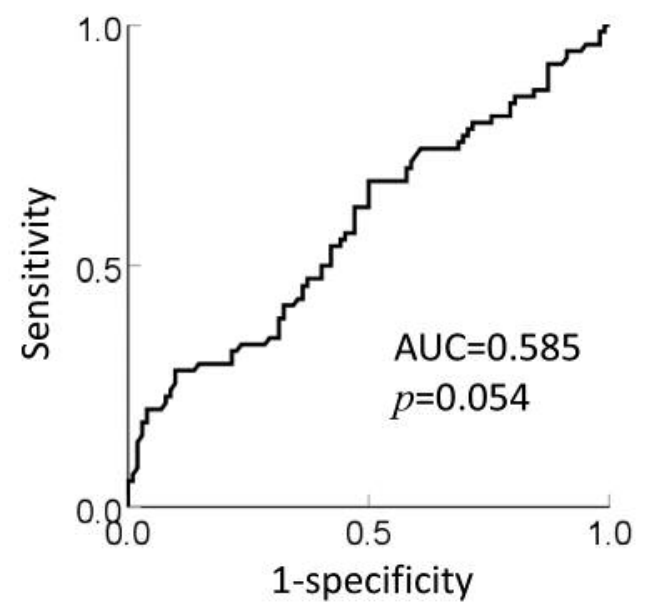

b

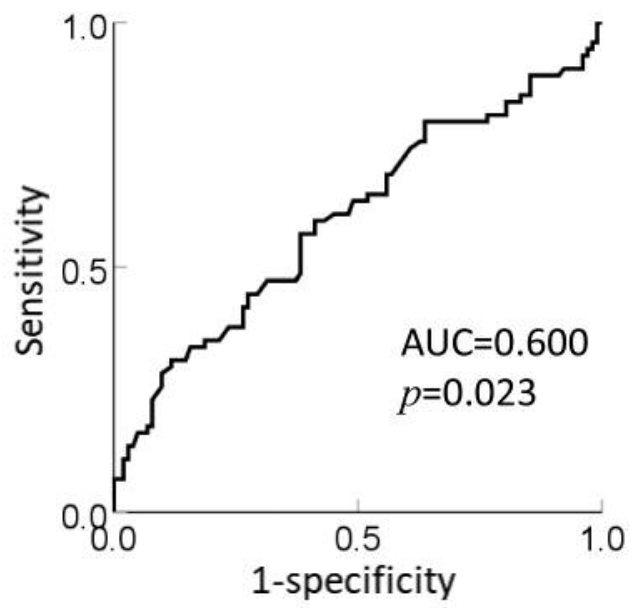

Figure 2. Comparison of areas under the receiver operating curves for outcome prediction between preoperative NLR (a) and preoperative Plt (b).

a

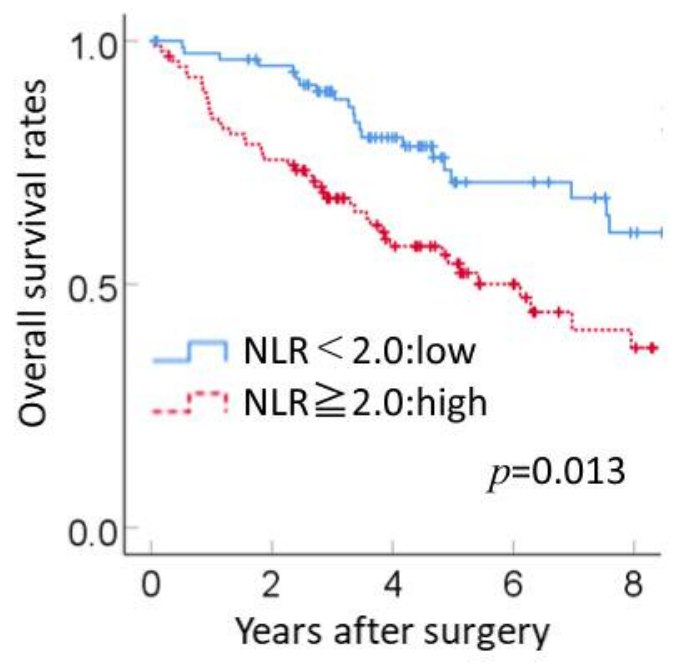

b

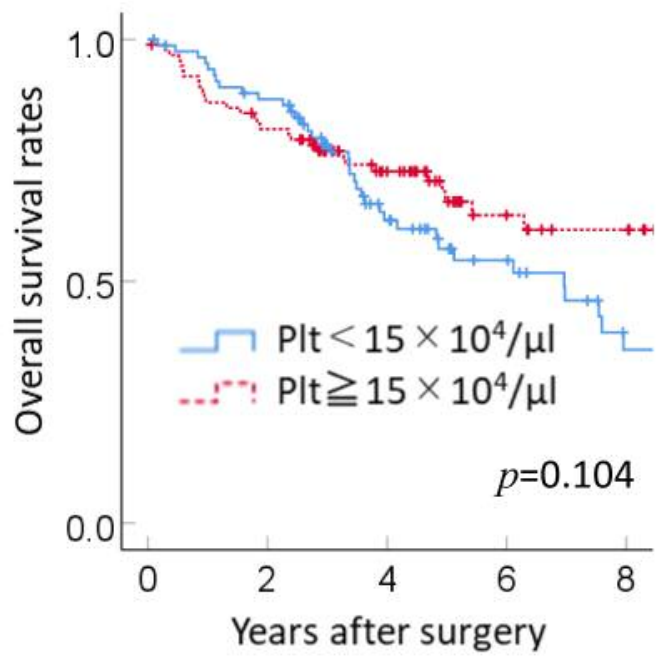

Figure 3. Overall survival curves based on preoperative NLR and preoperative Plt. (a) Preoperative NLR; 5-year survival rates were high NLR:

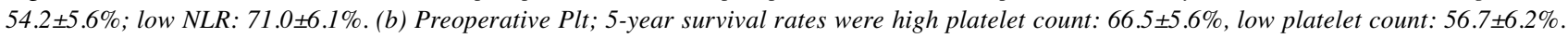

$p=0.030)$, and TNM stage $(\mathrm{HR}=2.271,95 \% \mathrm{CI}=1.276-4.041$, $p=0.005)$ were statistically significant. Multivariate analysis confirmed that h-COP-NLR $(\mathrm{HR}=1.390,95 \% \mathrm{CI}=1.031-1.876$, $p=0.031)$, and TNM stage $(\mathrm{HR}=2.410,95 \% \mathrm{CI}=1.351-4.301$, $p=0.003$ ) were independent recurrence factors (Table III).

\section{Discussion}

Our study assessed the prognostic value of pre-surgical h-COP-NLR in patients with HCC. We found that elevated
h-COP-NLR was significantly associated with shorter OS and RFS. Although several studies have shown relationships between COP-NLR and prognosis in various cancer types (10-14), to our knowledge, this study is the first to evaluate its pre-operative use in patients with HCC.

The COP-NLR originated from attempts to validate stratification of patients using prognostic parameters based on cellular inflammation, such as NLR and reactive thrombocytosis (20). First, NLR, which reflects both neutrophil count and lymphocyte count, is an indicator of 
Table I. Comparison of clinicopathological factors by $h$-COP-NLR status.

\begin{tabular}{|c|c|c|c|c|c|}
\hline & & \multicolumn{3}{|c|}{ Status of h-COP-NLR } & \multirow[t]{2}{*}{$p$-Value } \\
\hline & & $\begin{array}{c}0 \\
\mathrm{n}=38\end{array}$ & $\begin{array}{c}1 \\
\mathrm{n}=98\end{array}$ & $\begin{array}{c}2 \\
\mathrm{n}=40\end{array}$ & \\
\hline Age (years) & $\geq 65 /<65$ & $29 / 9$ & $70 / 28$ & $26 / 14$ & 0.541 \\
\hline Gender & Female/male & $2 / 36$ & $18 / 80$ & $9 / 31$ & 0.092 \\
\hline HBsAg & Positive/negative & $14 / 24$ & $37 / 61$ & $15 / 25$ & 0.995 \\
\hline $\mathrm{HCV}$ & Positive/negative & $10 / 28$ & $32 / 66$ & $17 / 23$ & 0.306 \\
\hline Diabetes mellitus & Yes/no & $14 / 24$ & $36 / 62$ & $12 / 28$ & 0.733 \\
\hline $\operatorname{AFP}(\mathrm{ng} / \mathrm{ml})$ & $\geq 10 /<10$ & $20 / 18$ & $48 / 50$ & $21 / 19$ & 0.894 \\
\hline Number & Multiple/single & $15 / 23$ & $19 / 79$ & $11 / 29$ & 0.052 \\
\hline Tumor size $(\mathrm{cm})$ & $\geq 5 /<5$ & $10 / 28$ & $27 / 71$ & $13 / 27$ & 0.800 \\
\hline Histotype & Poor/well or moderate & $3 / 35$ & $7 / 91$ & $4 / 36$ & 0.853 \\
\hline $\mathrm{vp}$ & $+/-$ & $17 / 21$ & $43 / 55$ & $17 / 23$ & 0.980 \\
\hline Stage & $\geq \mathrm{III} / \leq \mathrm{II}$ & $6 / 32$ & $8 / 90$ & $4 / 36$ & 0.419 \\
\hline Liver cirrhosis & Yes/no & $13 / 25$ & $31 / 67$ & $13 / 27$ & 0.959 \\
\hline
\end{tabular}

AFP: Alpha-fetoprotein; HBsAg: hepatitis B surface antigen; h-COP-NLR: hepatic combination of platelet count and NLR; HCV: hepatitis C virus; vp: microscopic portal vein invasion.

systemic inflammation and host immunity. Neutrophils, a component of NLR, are related to inflammation caused by tumors (21). Inflammatory responses are closely related to tumor development stage, including initiation, progression, malignant conversion, invasion, and metastasis (22). Circulating neutrophils induced from inflammation produce chemokines and cytokines, such as tumor necrosis factor, interleukin-1, interleukin-6, and vascular endothelial growth factor, which promote tumor proliferation, angiogenesis, invasion, and metastasis $(4,23,24)$. Lymphocytes are related to host immunity and suppress cancer progression by producing cytotoxic cell-death ligands and cytokines that inhibit tumor cell proliferation and metastasis (25-27). Therefore, several studies have associated high preoperative NLR with poor prognosis in HCC patients (28-30).

In the present study, we confirmed that low platelet count was both a predictor of poor prognosis and a significant prognostic addition to NLR in patients with HCC. In general, thrombocytosis generally occurs in $10 \%-57 \%$ of patients with cancer $(15,16)$. Thrombocytosis is reportedly a predictor of shorter survival in patients with various tumors (31-33), because the glycoprotein secreted by platelets affects migration, invasion and angiogenesis of tumor cells, and promotes tumor progression (34). However, among patients with liver disorders, when platelet count decreases, liver fibrosis is considered to have progressed (35). Multifocal carcinogenesis is reportedly likely to occur when fibrosis progresses in patients with chronic liver disease with hepatitis C (36). Low platelet counts are also reported to be a useful predictor for recurrence after radiofrequency ablation for HCC (37). These results suggest that low platelet count predicts poor prognosis in HCC. Our

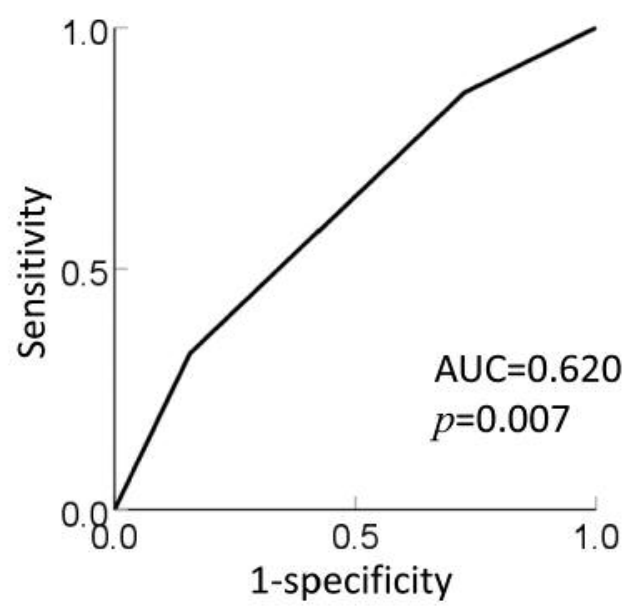

Figure 4. ROC survival curves for combined platelet count and NLR.

results also showed that low platelet count was a poor prognostic factor for HCC.

Our earlier study showed that NLR had limited prognostic capacity for HCC, as NLR alone did not predict HCC recurrence (38). We therefore added platelet count as a parameter into NLR (h-COP-NLR), which overcame this clinical issue. As all parameters of h-COP-NLR are included in ordinary complete blood count tests, h-COP-NLR is a simple and clinically significant predictor of prognosis of patients with HCC. In ROC analysis, the AUC of H-COP-NLR is higher than those of platelet number and NLR considered separately.

This study has some limitations - most obviously, its retrospective design, and small, single-institution cohort. 
Table II. Univariate and multivariate analyses of $h$-COP-NLR for prediction of OS.

\begin{tabular}{|c|c|c|c|c|c|c|c|}
\hline & & \multicolumn{3}{|c|}{ Univariate } & \multicolumn{3}{|c|}{ Multivariate } \\
\hline & & HR & $95 \% \mathrm{CI}$ & $p$-Value & HR & $95 \% \mathrm{CI}$ & $p$-Value \\
\hline Age (years) & $\geq 65 / 65>$ & 1.134 & $0.684-1.881$ & 0.626 & & & \\
\hline Gender & Female/male & 1.625 & $0.919-2.874$ & 0.095 & & & \\
\hline HBsAg & Positive/negative & 0.98 & $0.607-1.580$ & 0.933 & & & \\
\hline $\mathrm{HCV}$ & Positive/negative & 1.522 & $0.960-2.413$ & 0.074 & & & \\
\hline Diabetes mellitus & Yes/no & 1.029 & $0.634-1.669$ & 0.909 & & & \\
\hline NLR & $\geq 2 /<2$ & 1.81 & $1.128-2.903$ & 0.014 & 1.101 & $0.586-2.068$ & 0.766 \\
\hline Plt & $<150 / \leq 150$ & 1.463 & $0.923-2.318$ & 0.106 & & & \\
\hline h-COP-NLR & $2 / 1 / 0$ & 1.768 & $1.238-2.525$ & 0.002 & 1.714 & $1.073-2.739$ & 0.024 \\
\hline $\operatorname{AFP}(\mathrm{ng} / \mathrm{ml})$ & $\geq 10 /<10$ & 1.56 & $0.980-2.483$ & 0.061 & & & \\
\hline Surgery duration (min) & $\geq 360 /<360$ & 1.086 & $0.668-1.766$ & 0.739 & & & \\
\hline Extent of resection & Major/minor & 0.935 & $0.582-1.500$ & 0.935 & & & \\
\hline Number & Multiple/single & 1.253 & $0.760-2.067$ & 0.376 & & & \\
\hline Tumor size $(\mathrm{cm})$ & $\geq 5 /<5$ & 1.588 & $0.985-2.559$ & 0.058 & & & \\
\hline Histotype & Poor/well or moderate & 1.969 & $0.939-4.130$ & 0.073 & & & \\
\hline $\mathrm{vp}$ & $+/-$ & 1.065 & $0.673-1.685$ & 0.787 & & & \\
\hline Stage & $\geq \mathrm{III} / \leq \mathrm{II}$ & 2.319 & $1.204-4.464$ & 0.012 & 2.45 & $1.261-4.759$ & 0.008 \\
\hline Liver cirrhosis & Yes/no & 0.887 & $0.543-1.448$ & 0.631 & & & \\
\hline
\end{tabular}

AFP: Alpha-fetoprotein; HBsAg: hepatitis B surface antigen; h-COP-NLR: hepatic combination of platelet count and NLR; HCV: hepatitis C virus; NLR: neutrophil to lymphocyte ratio; OS: overall survival; vp: microscopic portal vein invasion.

Table III. Univariate and multivariate analyses of $h$-COP-NLR for prediction of recurrence-free survival.

\begin{tabular}{|c|c|c|c|c|c|c|c|}
\hline & & \multicolumn{3}{|c|}{ Univariate analysis } & \multicolumn{3}{|c|}{ Multivariate analysis } \\
\hline & & HR & $95 \% \mathrm{CI}$ & $p$-Value & HR & $95 \% \mathrm{CI}$ & $p$-Value \\
\hline Age (years) & $\geq 65 /<65$ & 1.257 & $0.819-1.927$ & 0.295 & & & \\
\hline Gender & Female/male & 1.638 & $1.003-2.677$ & 0.049 & 1.411 & $0.85-2.342$ & 0.183 \\
\hline HBsAg & Positive/negative & 0.926 & $0.62-1.385$ & 0.71 & & & \\
\hline $\mathrm{HCV}$ & Positive/negative & 1.014 & $0.68-1.51$ & 0.947 & & & \\
\hline Diabetes mellitus & Yes/no & 1.205 & $0.812-1.786$ & 0.354 & & & \\
\hline NLR & $\geq 2 /<2$ & 1.423 & $0.969-2.089$ & 0.072 & & & \\
\hline Plt & $<150 / \leq 150$ & 1.319 & $0.901-1.929$ & 0.154 & & & \\
\hline h-COP-NLR & $2 / 1 / 0$ & 1.452 & $1.081-1.948$ & 0.013 & 1.39 & $1.031-1.876$ & 0.031 \\
\hline $\operatorname{AFP}(\mathrm{ng} / \mathrm{ml})$ & $\geq 10 /<10$ & 1.531 & $1.041-2.251$ & 0.03 & 1.47 & $0.997-2.166$ & 0.052 \\
\hline Surgical duration (min) & $\geq 360 /<360$ & 1.074 & $0.719-1.605$ & 0.726 & & & \\
\hline Extent of resection & Major/minor & 0.976 & $0.662-1.438$ & 0.901 & & & \\
\hline Number & Multiple/single & 1.062 & $0.692-1.631$ & 0.783 & & & \\
\hline Tumor size $(\mathrm{cm})$ & $\geq 5 /<5$ & 1.258 & $0.834-1.896$ & 0.274 & & & \\
\hline Histotype & Poor/well or moderate & 1.891 & $0.979-3.653$ & 0.058 & & & \\
\hline $\mathrm{vp}$ & $+/-$ & 0.975 & $0.664-1.431$ & 0.896 & & & \\
\hline Stage & $\geq \mathrm{III} / \leq \mathrm{II}$ & 2.271 & $1.276-4.041$ & 0.005 & 2.41 & $1.351-4.301$ & 0.003 \\
\hline Liver cirrhosis & Yes/no & 0.918 & $0.610-1.383$ & 0.683 & & & \\
\hline
\end{tabular}

AFP: Alpha-fetoprotein; HBsAg: hepatitis B surface antigen; h-COP-NLR: hepatic combination of platelet count and NLR; HCV: hepatitis C virus; NLR: neutrophil to lymphocyte ratio; OS: overall survival; vp: microscopic portal vein invasion.

Therefore, further studies are needed to validate our results.

In conclusion, h-COP-NLR was an independent predictor for prognosis in HCC patients who undergo initial surgery, and may be a novel biomarker of HCC prognosis. Because h-COP-NLR can be evaluated only with routine peripheral blood tests, it is a very convenient and effective index for HCC patients. 
a

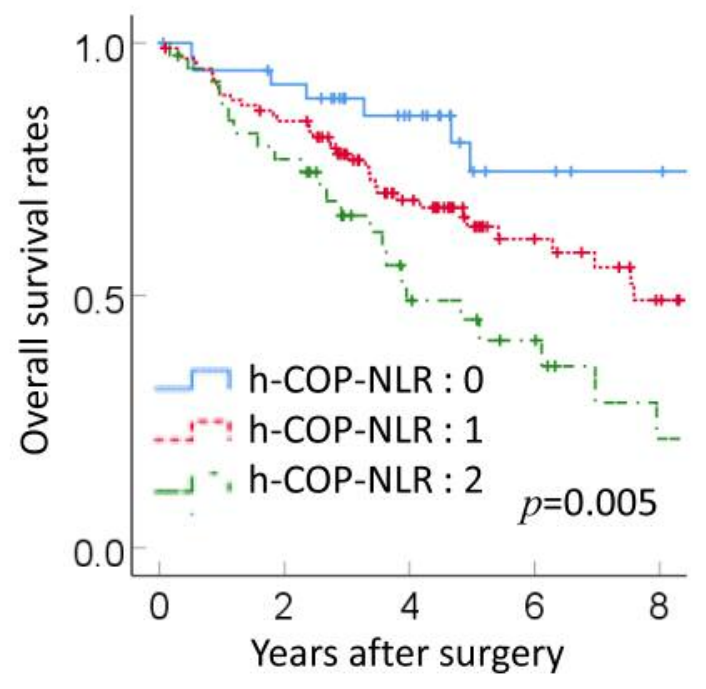

b

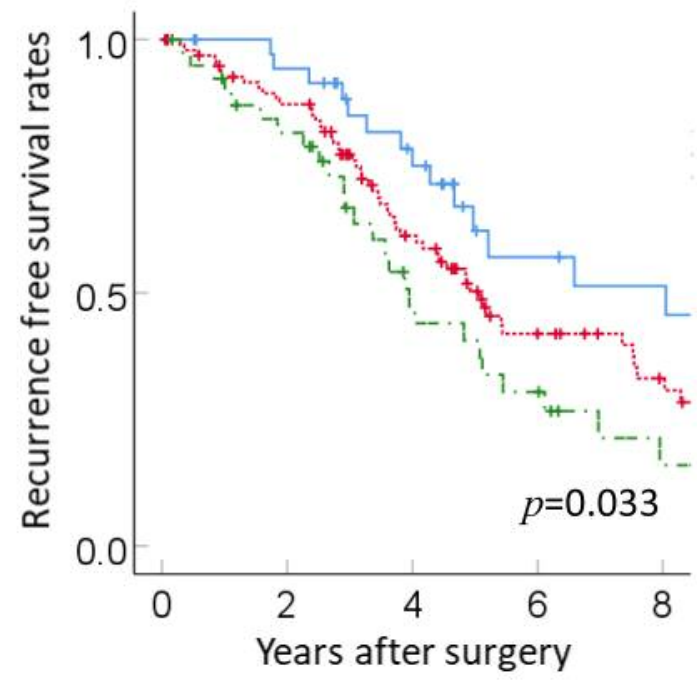

Figure 5. (a) The Kaplan-Meier method and log rank test showed 5-year OS rates to be significantly different ( $p=0.005)$ at $h$-COP-NLR 0: 74.5 $\pm 9 \%$, $h$-COP-NLR 1: 63.6 $\pm 5.4 \%$, and $h$-COP-NLR 2: 45.2 $\pm 8.8 \%$; (b) 5-year recurrence-free survival rates were also significantly different ( $p=0.033$ ) at h-COP-NLR 0: $62.2 \pm 9.3 \%, h$-COP-NLR 1: $50.3 \pm 5.6 \%$ 1, and h-COP-NLR 2: 40.6 $\pm 8.7 \%$ in $h$-COP-NLR 2.

\section{Conflicts of Interest}

The Authors declare no conflicts of interest in association with this study.

\section{Acknowledgements}

The Authors would like to thank Marla Brunker, from Edanz Group (www.edanzediting.com/ac), for editing a draft of this manuscript.

\section{Authors' Contributions}

E.U. Designed the study. E.U., M.A., T.Y., M.M., J.W., N.T., T.S., S.H., and H.S. collected data. E.U. analyzed the data. E.U., M.A. and Y.F. wrote the article. All Authors declare they significantly participated in creation of the study. All Authors read and approved the final article.

\section{References}

1 Setshedi M, Andersson M, Kgatle MM and Roberts L: Molecular and cellular oncogenic mechanisms in hepatocellular carcinoma. S Afr Med J 108: 41-46, 2018. PMID: 30182912. DOI: 10.7196/SAMJ.2018.v108i8b.13500

2 Khalaf N, Ying J, Mittal S, Temple S, Kanwal F, Davila J and El-Serag HB: Natural history of untreated hepatocellular carcinoma in a US cohort and the role of cancer surveillance. Clin Gastroenterol Hepatol 15: 273-281.e271, 2017. PMID: 27521507. DOI: $10.1016 /$ j.cgh.2016.07.033

3 National Cancer Institute: Surveillance, Epidemiology, and End Results (SEER) Program. SEER*Stat database, 1973-2007. Available at: https://seer.cancer.gov/ (last accessed 17/09/2019)
4 Balkwill $\mathrm{F}$ and Mantovani A: Inflammation and cancer: back to Virchow? Lancet 357: 539-545, 2001. PMID: 11229684. DOI: 10.1016/S0140-6736(00)04046-0

5 Mantovani A, Allavena P, Sica A and Balkwill F: Cancer-related inflammation. Nature 454: 436-444, 2008. PMID: 18650914. DOI: $10.1038 /$ nature 07205

6 Wang Y, Peng C, Cheng Z, Wang X, Wu L, Li J, Huang C, Guo $Q$ and Cai $\mathrm{H}$ : The prognostic significance of preoperative neutrophil-lymphocyte ratio in patients with hepatocellular carcinoma receiving hepatectomy: A systematic review and meta-analysis. Int J Surg 55: 73-80, 2018. PMID: 29787804. DOI: $10.1016 /$ j.ijsu.2018.05.022

7 Abe T, Tashiro H, Kobayashi T, Hattori M, Kuroda S and Ohdan $\mathrm{H}$ : Glasgow prognostic score and prognosis after hepatectomy for hepatocellular carcinoma. World J Surg 41: 1860-1870, 2017. PMID: 28197709. DOI: 10.1007/s00268-017-3909-7

8 Kinoshita A, Onoda H, Imai N, Iwaku A, Oishi M, Tanaka K, Fushiya N, Koike K, Nishino H and Matsushima M: The Creactive protein/albumin ratio, a novel inflammation-based prognostic score, predicts outcomes in patients with hepatocellular carcinoma. Ann Surg Oncol 22: 803-810, 2015. PMID: 25190127. DOI: 10.1245/s10434-014-4048-0

9 Zheng J, Cai J, Li H, Zeng K, He L, Fu H, Zhang J, Chen L, Yao J, Zhang Y and Yang Y: Neutrophil to lymphocyte ratio and platelet to lymphocyte ratio as prognostic predictors for hepatocellular carcinoma patients with various treatments: a meta-analysis and systematic review. Cell Physiol Biochem 44: 967-981, 2017. PMID: 29179180. DOI: 10.1159/000 485396

10 Tsujino T, Komura K, Ichihashi A, Tsutsumi T, Matsunaga T, Yoshikawa Y, Maenosono R, Okita K, Takai T, Oide R, Minami $\mathrm{K}$, Uehara $\mathrm{H}$, Taniguchi $\mathrm{K}$, Hirano $\mathrm{H}$, Nomi $\mathrm{H}$, Ibuki $\mathrm{N}$, Takahara $\mathrm{K}$, Inamoto $\mathrm{T}$ and Azuma $\mathrm{H}$ : The combination of 
preoperative platelet count and neutrophil lymphocyte ratio as a prognostic indicator in localized renal cell carcinoma. Oncotarget 8: 110311-110325, 2017. PMID: 29299149. DOI: 10.18632 /oncotarget 22688

11 Feng JF, Huang Y and Chen QX: The combination of platelet count and neutrophil lymphocyte ratio is a predictive factor in patients with esophageal squamous cell carcinoma. Transl Oncol 7: 632-637, 2014. PMID: 25389458. DOI: 10.1016/j.tranon. 2014.07.009

12 Zhang H, Zhang L, Zhu K, Shi B, Yin Y, Zhu J, Yue D, Zhang $B$ and Wang C: Prognostic significance of combination of preoperative platelet count and neutrophil-lymphocyte ratio (COP-NLR) in patients with non-small cell lung cancer: Based on a large cohort study. PloS One 10: e0126496, 2015. PMID: 25950176. DOI: 10.1371/journal.pone.0126496

13 Nakayama M, Gosho M, Hirose Y, Nishimura B, Tanaka S, Tabuchi $\mathrm{K}$, Okubo $\mathrm{H}$, Wada $\mathrm{T}$ and Hara A: Modified combination of platelet count and neutrophil "to" lymphocyte ratio as a prognostic factor in patients with advanced head and neck cancer. Head Neck 40: 1138-1146, 2018. PMID: 29385295. DOI: $10.1002 /$ hed .25085

14 Ishizuka M, Nagata H, Takagi K, Iwasaki Y and Kubota K: Combination of platelet count and neutrophil to lymphocyte ratio is a useful predictor of postoperative survival in patients with colorectal cancer. Br J Cancer 109: 401-407, 2013. PMID: 23820256. DOI: $10.1038 /$ bjc.2013.350

15 Proctor MJ, McMillan DC, Morrison DS, Fletcher CD, Horgan PG and Clarke SJ: A derived neutrophil to lymphocyte ratio predicts survival in patients with cancer. Br J Cancer 107: 695699, 2012. PMID: 22828611. DOI: 10.1038/bjc.2012.292

16 Naito S, Yamamoto N, Takayama T, Muramoto M, Shinohara N, Nishiyama K, Takahashi A, Maruyama R, Saika T, Hoshi S, Nagao K, Yamamoto S, Sugimura I, Uemura H, Koga S, Takahashi M, Ito F, Ozono S, Terachi T, Naito S and Tomita Y: Prognosis of Japanese metastatic renal cell carcinoma patients in the cytokine era: a cooperative group report of 1463 patients. Eur Urol 57: 317-325, 2010. PMID: 19136199. DOI: 10.1016/ j.eururo.2008.12.026

17 Hayashi H, Beppu T, Shirabe K, Maehara Y and Baba H: Management of thrombocytopenia due to liver cirrhosis: a review. World J Gastroenterol 20: 2595-2605, 2014. PMID: 24627595. DOI: $10.3748 / w j g . v 20 . i 10.2595$

18 Liver Cancer Study Group of Japan: The general rules for the clinical and pathological study of primary liver cancer. Tokyo: Kanehara, 2009.

19 Zahorec R: Ratio of neutrophil to lymphocyte counts--rapid and simple parameter of systemic inflammation and stress in critically ill. Bratisl Lek Listy 102: 5-14, 2001. PMID: 11723675.

20 Ishizuka M, Oyama Y, Abe A and Kubota K: Combination of platelet count and neutrophil to lymphocyte ratio is a useful predictor of postoperative survival in patients undergoing surgery for gastric cancer. J Surg Oncol 110: 935-941, 2014. PMID: 25146385. DOI: 10.1002/jso.23753

21 Diakos CI, Charles KA, McMillan DC and Clarke SJ: Cancerrelated inflammation and treatment effectiveness. Lancet Oncol 15: e493-503, 2014. PMID: 25281468. DOI: 10.1016/S14702045(14)70263-3

22 Grivennikov SI, Greten FR and Karin M: Immunity, inflammation, and cancer. Cell 140: 883-899, 2010. PMID: 20303878. DOI: 10.1016/j.cell.2010.01.025
23 Rivas-Fuentes S, Salgado-Aguayo A, Pertuz Belloso S, Gorocica Rosete P, Alvarado-Vasquez N and Aquino-Jarquin G: Role of chemokines in non-small cell lung cancer: angiogenesis and inflammation. J Cancer 6: 938-952, 2015. PMID: 26316890. DOI: $10.7150 /$ jca. 12286

24 Kusumanto YH, Dam WA, Hospers GA, Meijer C and Mulder $\mathrm{NH}$ : Platelets and granulocytes, in particular the neutrophils, form important compartments for circulating vascular endothelial growth factor. Angiogenesis 6: 283-287, 2003. PMID: 15166496. DOI: 10.1023/B:AGEN.0000029415.62384.ba

25 Liao W, Zhang J, Zhu Q, Qin L, Yao W, Lei B, Shi W, Yuan S, Tahir SA, Jin J and He S: Preoperative neutrophil-to-lymphocyte ratio as a new prognostic marker in hepatocellular carcinoma after curative resection. Transl Oncol 7: 248-255, 2014. PMID: 24704092. DOI: 10.1016/j.tranon.2014.02.011

26 Dunn GP, Old LJ and Schreiber RD: The immunobiology of cancer immunosurveillance and immunoediting. Immunity 21 : 137-148, 2004. PMID: 15308095. DOI: 10.1016/j.immuni. 2004.07.017

27 Ding PR, An X, Zhang RX, Fang YJ, Li LR, Chen G, Wu XJ, Lu ZH, Lin JZ, Kong LH, Wan DS and Pan ZZ: Elevated preoperative neutrophil to lymphocyte ratio predicts risk of recurrence following curative resection for stage IIA colon cancer. Int J Colorectal Dis 25: 1427-1433, 2010. PMID: 20821217. DOI: $10.1007 / \mathrm{s} 00384-010-1052-0$

28 Gomez D, Farid S, Malik HZ, Young AL, Toogood GJ, Lodge JP and Prasad KR: Preoperative neutrophil-tolymphocyte ratio as a prognostic predictor after curative resection for hepatocellular carcinoma. World J Surg 32: 1757-1762, 2008. PMID: 18340479. DOI: $10.1007 / \mathrm{s} 00268-$ 008-9552-6

29 Hung HC, Lee JC, Cheng CH, Wu TH, Wang YC, Lee CF, Wu TJ, Chou HS, Chan KM and Lee WC: Impact of neutrophil to lymphocyte ratio on survival for hepatocellular carcinoma after curative resection. J Hepatobiliary Pancreat Sci 24: 559-569, 2017. PMID: 28846835. DOI: 10.1002/jhbp.498

30 Galun D, Bogdanovic A, Djokic Kovac J, Bulajic P, Loncar Z and Zuvela M: Preoperative neutrophil-to-lymphocyte ratio as a prognostic predictor after curative-intent surgery for hepatocellular carcinoma: experience from a developing country. Cancer Manage Res 10: 977-988, 2018. PMID: 29765248. DOI: 10.2147/CMAR.S161398

31 Shimada H, Oohira G, Okazumi S, Matsubara H, Nabeya Y, Hayashi H, Takeda A, Gunji Y and Ochiai T: Thrombocytosis associated with poor prognosis in patients with esophageal carcinoma. J Am Coll Surg 198: 737-741, 2004. PMID: 15110807. DOI: 10.1016/j.jamcollsurg.2004.01.022

32 Ikeda M, Furukawa H, Imamura H, Shimizu J, Ishida H, Masutani S, Tatsuta M and Satomi T: Poor prognosis associated with thrombocytosis in patients with gastric cancer. Ann Surg Oncol 9: 287-291, 2002. PMID: 11923136.

33 Ishizuka M, Nagata H, Takagi K, Iwasaki Y and Kubota K: Preoperative thrombocytosis is associated with survival after surgery for colorectal cancer. J Surg Oncol 106: 887-891, 2012. PMID: 22623286. DOI: $10.1002 /$ jso.23163

34 Tuszynski GP and Nicosia RF: The role of thrombospondin-1 in tumor progression and angiogenesis. BioEssays 18: 71-76, 1996. PMID: 8593167 . DOI: 10.1002/bies.950180113

35 Ono E, Shiratori Y, Okudaira T, Imamura M, Teratani T, Kanai F, Kato N, Yoshida H, Shiina S and Omata M: Platelet count 
reflects stage of chronic hepatitis C. Hepatol Res 15: 192-200, 1999. DOI: $10.1016 / \mathrm{S} 1386-6346(98) 00075-8$

36 Kubo S, Yamamoto T, Ikebe T, Shuto T, Hirohashi K, Tanaka H, Tsukamoto T, Wakasa K and Kinoshita H: Relationship between multicentric occurrence of hepatocellular carcinoma and histology of noncancerous hepatic tissue in patients with chronic hepatitis C. Jap J Cancer Res 90: 1076-1080, 1999. PMID: 10595735. DOI: 10.1111/j.1349-7006.1999.tb00680.x

37 Hikita H, Tanaka Y, Shigekawa M, Mukai K, Nakamura K, Song C, Tatumi O, Inoue Y, Sasagawa A, Nakanishi F, Masuda E and Hijioka T: Predictive factors for intrahepatic distant recurrence of hepatocellular carcinoma after radiofrequency ablation for primary tumors. Acta Hepatol Jap 47: 209-216, 2006. DOI: 10.2957/kanzo.47.209
38 Uchinaka E, Amisaki M, Morimoto M, Tokuyasu N, Sakamoto T, Honjo S, Saito H and Fujiwara Y: Utility and limitation of preoperative neutrophil lymphocyte ratio as a prognostic factor in hepatocellular carcinoma. Yonago Acta Med 61: 197-203, 2018. PMID: 30636915.
Received August 16, 2019

Revised September 16, 2019 Accepted September 17, 2019 